\title{
SCAFFolding Strategies for Teaching EngineERING DeSign in a Collaborative Project-Based Learning Environment
}

\author{
Mohamed Galaleldin, Hanan Anis, Patrick Dumond, and David Knox \\ University of Ottawa \\ mgalalel@uottawa.ca, hanis@uottawa.ca,pdumond@uottawa.ca,dknox@uottawa.ca
}

\begin{abstract}
Collaborative Project Based Learning (CPBL) is known for enhancing deep learning, professional skills development, student engagement and motivation, cultivating interdependence in learning, thinking, problem solving, and creating interest and excitement in learning. This article describes the impact of an engineering design course on first-year engineering students. Student performance was evaluated before and after taking the course using a pre-and-post design skill assessment test, peer feedback evaluations, and thematic analysis of each student's self-reflection of lessons learned. Initial analysis of the data indicates that a CPBL environment has a significantly positive impact on the development of engineering students' ability to describe the engineering design process and relate it directly to real-world problems. Students also realized the importance of communication, team work, investigation and project management skills.
\end{abstract}

Keywords: Collaborative Project Based Learning, Scaffolding, Engineering Design Education.

\section{INTRODUCTION}

Engineering design education's role in engineering curricula is to equip graduating engineers with the skills necessary for them to excel at applying the design process, team-based design and design communication [4]. Wood has argued that engineering students must be introduced to experimentation courses in the context of engineering projects as it plays a role in the verification of theory and each student's ability to test their designs by building prototypes [12].

Engineering design is a systematic process in which designers generate, evaluate, and specify concepts for devices, systems, or processes whose form and function achieve clients' objectives or users' needs while satisfying a specified set of constraints. This is often conducted with imperfect models, incomplete information and with ambiguous objectives. Engineering educators have been emphasizing conceptual understanding, using more hands- on teaching methods, and using more graphics and simulations to overcome these difficulties [7].

This paper reports on the initial observations and analysis based on the data collected from teaching an engineering design course based on a collaborative projectbased learning (CPBL) environment, and the scaffolding strategies used to facilitate student learning. Scaffolding in this article refers to situations in which a student gets assistance or support that enables them to perform a task beyond his or her own unassisted efforts if pursued independently when "unassisted" [11]. CPBL is an instructional strategy that aims to engage students in authentic activity to enhance learning, and where an individual or group engage in an activity that goes on over a period of time with a timeline and milestones, resulting in a product, presentation, or performance [5]. The course understudy in this article used for the collaborative projectbased learning environment scaffolds students into working in groups to solve engineering problems using face-to-face interactions with real clients and users following the design thinking methodology.

Carroll et al. proposed design thinking as an approach to learning that focuses on developing students' creative confidence through hands-on projects that focus on empathy, promoting a bias towards action, encouraging ideation and fostering active problem-solving [2]. It is noted that its power as a tool for learning comes in the ways it can support a diverse range of interdisciplinary academic content.

Many engineering educators provide team oriented cornerstone and capstone projects to improve students' ability to function as effective team members before entering the workforce, to simulate industry conditions, and to improve students' interpersonal and leadership skills, and their ability to tackle large projects [6].

Duston et al. recommend allowing students to form their own teams, as this approach to team formation allows students to work with their peers whom they know and with whom they will likely get along.

Students face several challenges working in a team environment, as it represents a new experience for many engineering students coming out of high school. Pournaghshband administered a survey to students at the 
end of a team oriented design course to understand the problems students had faced during the course and identified six important factors to a team's success: communication, compromise, commitment, leadership, innovation, and assertiveness [10].

Davis et al. noted that engineering educators who teach engineering design must be able to understand teamwork, the engineering design process and effective engineering design communication skills [4]. They also note that educators must define the learning outcomes of their teaching at different points in the curricula, utilize methods that can help students develop the desired engineering competencies and be able to assess student progress and achievements. They conclude with three types of engineering design learning outcomes that are important: design knowledge, design process skills and design products. Assessments must allow students to demonstrate these three types of capabilities.

\section{ENGINEERING DESIGN COURSE}

The course described in this paper is a three-hour credit, hands-on, team-based introduction to engineering design for engineers and computer scientists offered as mandatory course to all first year civil and electrical engineering students at the University of Ottawa. Topics covered in the course include design thinking, engineering design process, prototyping and testing, communication, and project management. Engineering case studies were used to actively engage students in their learning. Cases were used to provide students with a practical context, showing the real-world applications of engineering design [13].The main learning objective of the course was to provide students with the skills required to design products/services in the real world.

To facilitate learning, a number of scaffolding strategies were used in the course:

- Design Thinking: engaging students in a projectbased learning environment that allows them to empathize with clients to recognize their needs, define their problem statement, and participate in an iterative cycle of ideation, prototyping, and iteration centred on client feedback;

- Use of engineering tools: introducing students to tools that can help them develop their prototypes such as Arduino, MATLAB, SOLIDWORKS and machine shop training;

- Communication Skills: improving students' communication skills by providing lectures focused on communication skills, engaging students by asking them to present their work in class, and in front of clients on design day;

- Project Management: introducing students to project management skills that can help them with developing their prototypes. The fundamentals were taught in a lecture. Students had to use Microsoft Project as a part of a lab, and a project deliverable was dedicated to project management;

- Individual and Team Work: Students were introduced to the importance of team communication and conflict management in the lecture. Members of each team had to fill two team dynamics and peer evaluation feedback assessments and have a team debrief meeting facilitated by teaching assistants to identify dysfunctional teams and help them improve their individual and teamwork skills [14].

Students worked in groups based on their preference and interest in a project from four main project opportunities. Students had to select a project by the second week of the course. The themed engineering projects proposed to students were: a net energy automated shed, three types of hydroponic systems (sustainable produce for the food services at the University of Ottawa, biology and technology education for the Ottawa Catholic School Board, easier access to better food in refugee camps for Syrian refugees), robotics, and wearable technology projects that aim to integrate art and technology in a STEAM punk theme for the Canada 150 celebration.

Students worked in groups of 4-5 (in most cases) to solve their clients' engineering problem while following the design thinking methodology as they empathized with their clients while trying to understand the problem and the solutions their clients were looking for. They then proceeded to define the problem and come up with a problem a statement, ideate several solutions using several ideation strategies, develop conceptual and detailed designs and finally create and test prototypes. Throughout the process students met with their clients a minimum of three times during the course (although they were encouraged to meet with them more often). These meetings occurred at the beginning of the course to understand their requirements and to empathize with them, midway through the course to get feedback for their first prototype, and a third time after completing their final prototype. Moreover, students also attended a lab in which they learned about a variety of tools in the first part of the term (prior to reading week) and to work on their group projects in the second part of the term.

Each week students attended two one and a half hour lectures and a three-hour lab. During the lab, teaching assistants assumed the role of mentors for the groups that were in their lab sections, which helped facilitate student progress, made sure that their questions were answered promptly and ensured that students were making progress in submitting their project deliverables and building their prototypes. Students were required to deliver ten project deliverables:

1. Team formation and contract 


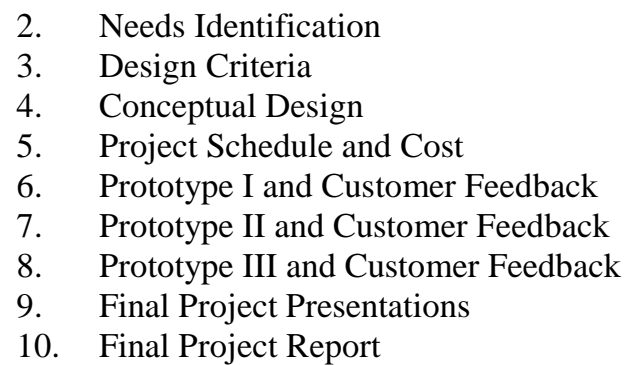

Students were provided \$100CAD per group to purchase materials they needed in developing their prototypes. Moreover, students had unrestricted access to resources available at the Richard L'Abbé Makerspace (rapid prototyping) and the Brunsfield Centre (traditional fabrication) [9]. All final prototypes were presented at the Faculty of Engineering Design Day, where students showcased their prototypes to their fellow peers, faculty members, invited industry representatives and a significant amount of external media. Final designs were judged by a committee composed of clients and faculty members.

\section{RESEARCH OBJECTIVES}

The objective of this article is to identify the impact of an introductory engineering design course on student engineering skills and how student performance as part of a team corresponds with their overall performance in the course.

\section{RESEARCH METHODOLOGY}

\subsection{Pre-Post Study}

A pre-post intervention test was administered to measure the course's impact on student design skills. In this paper a design skill assessment (DSA) tool proposed by Frank and Strong was used to measure student design skills before and after taking the course [8]. In the first lecture, students were asked to describe the process they would follow to design a tricycle, outlining all special considerations, specific requirements associated with their designs and all the steps they would follow to solve the problem. The DSA rubric developed by Frank and Strong was modified to account for the design thinking theme of this course. Need identification was added to the rubric as the first step of the design process (see appendix A for the need identification stage added to the rubric). A sample of 47 student submissions were corrected by two researchers and verified to ensure inter-rater reliability. The post-test was executed as part of the final exam for the course. Students were asked to outline the design process they would follow to design an engineering solution for their course project.

\subsection{Assessment of Team Work}

Team work accounted for $30 \%$ of the final mark for this course. We used the University of Calgary's Individual and Team Performance lab (ITP) peer feedback assessment tool [14] to assess students' contribution to their project work and team dynamics. The tool helps team members become aware of their strengths and weakness, performance as a group, and development opportunities to improve their teamwork. Students were asked to provide feedback and rate their team members on five competencies that are related to team effectiveness. The five competencies were commitment, communication, knowledge, skills and abilities (KSAs), standards and focus. Students rate their peers on a scale of 1 to 5,1 being unsatisfactory and 5 being outstanding. A report is provided to each team member summarizing their team members' feedback and team debrief template that facilitates a team meeting to discuss the results from the peer feedback assessment and identify development goals.

\subsection{Lessons Learned}

Students were asked to reflect on the lessons learned while working on their projects and present it in their final presentations at the end of the course as a project deliverable. Presentations slides were collected through Blackboard Learn, University of Ottawa's e-learning system. Aiming to discover students' reflection on the learning outcomes and engineering skills impacted by their project experience, student submissions were analyzed using thematic analysis techniques. Thematic analysis is a method for identifying, analyzing and reporting patterns within data. Thematic Analysis defines themes as a rich description of the data set, or a detailed account of one aspect that is important in relation to the overall research question [1]. Initial codes were generated, after which the data was coded looking for common themes of learning outcomes that were most impacted by the course.

\section{RESULTS AND DISCUSSION}

\subsection{Pre-Post Results}

The pre-post DSA tool was administered to 235 students, of which an initial sample of 48 student responses were analyzed for this article. The course was offered in the winter semester of 2017 by four professors. Two researchers assessed student responses, and a small sample of the responses were analyzed by a third marker. Submissions were marked after agreement and modifications to the language of the rubric.

Students showed considerable progress in their design skills by the end of the course. During the course students were required to select a project that they were interested 
in, meet with their client, identify the client's problem, propose several engineering solutions to the client's problem, select a final idea, develop a conceptual and detailed designs, participate in an iterative process of improving their prototypes by gathering feedback from their client, and present their final prototypes to their instructors and peers. These learning activities contributed to student design skills improvement. Students were very engaged during the course as they felt they were solving real problems with their designs. Fig. 1 presents the results of the pre-post DSA test administered to students. The course has helped students improve their design skills, with all students showing a substantial improvement in their design capabilities at the end of the course. The average for the pre-test marks was $14 \%$ with one student scoring $42 \%$ as that student had taken a previous design course in the fall semester, while the average for the post-test was $73 \%$. Fig. 2 presents each students' progress (change in their mark) before and after they took the course.

One of the intentions of this study was to understand the relationship between team dynamics and project outcomes. Each student's contribution to the group work (average of peer feedback rating normalized per group) was plotted against the average project mark for each team (see Fig. 3). The project mark represents sum of all the marks of the 10 project deliverables.

Most of the groups in the course worked well together, except for two dysfunctional teams. From the analysis of the data we observed that both dysfunctional teams ended up with a lower average project mark.

It is expected that the scaffolding strategies used to facilitate student team work, and conflict management significantly helped in limiting the number of dysfunctional teams.

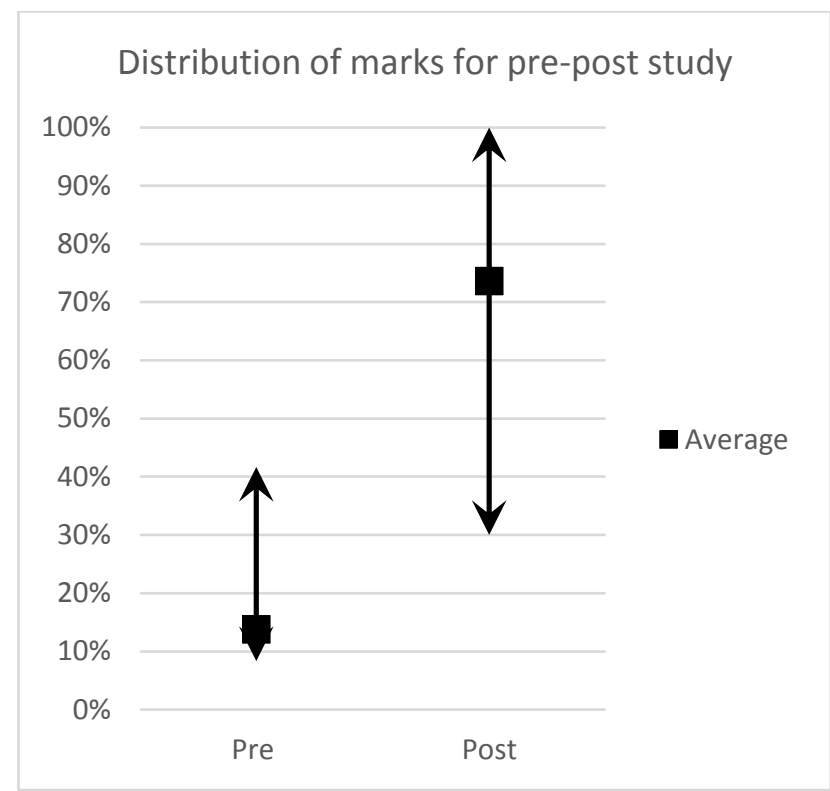

Fig. 1. Distribution of marks for the pre and post DSA test.

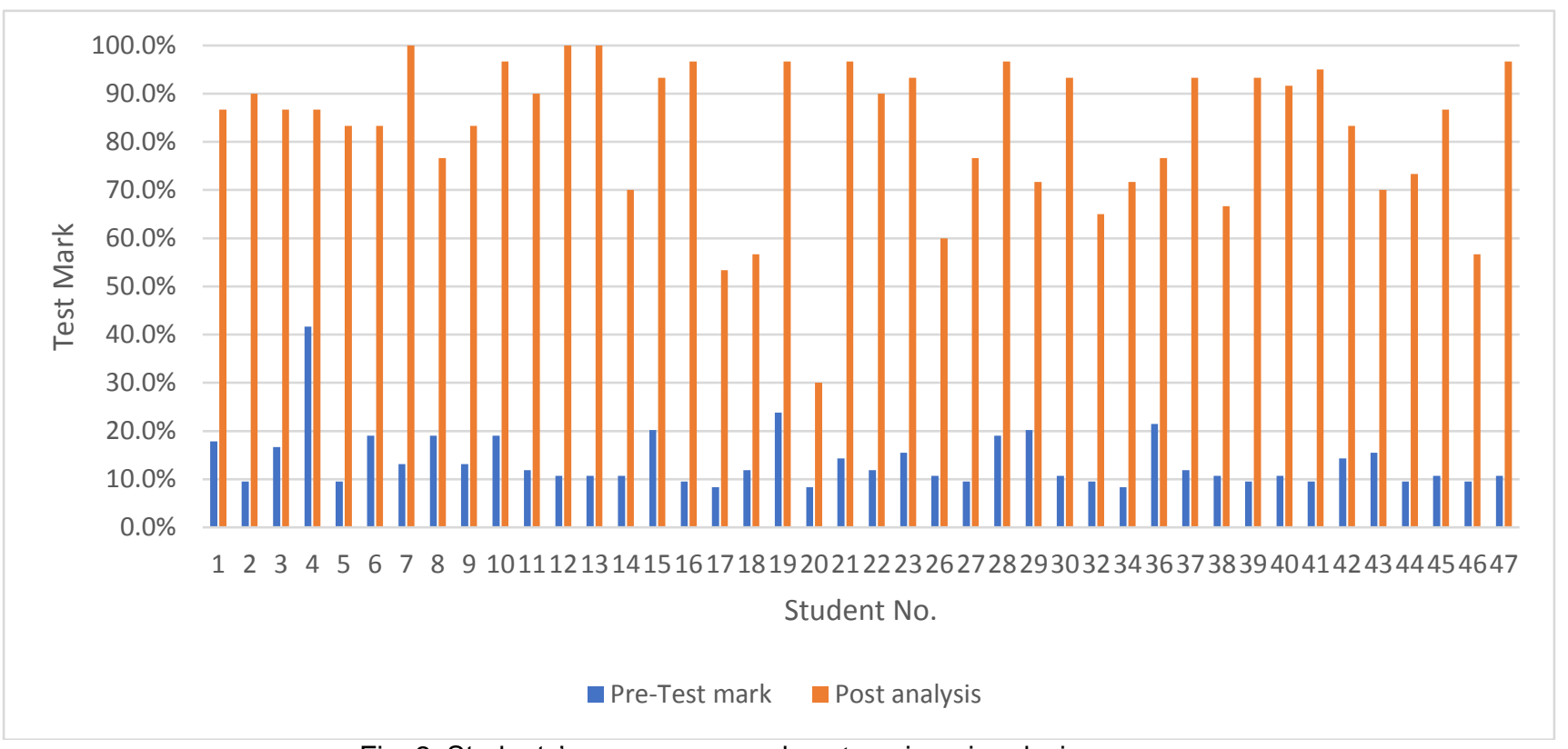

Fig. 2. Students' progress pre and post engineering design course.

\subsection{Lessons Learned}

All the lessons learned mentioned in students' presentations were coded using thematic analysis and categorized to five main categories that fall under the CEAB graduate attributes [3]: Design, Individual and
Team Work, Engineering Knowledge, Project Management, Communication, and Investigation Skills. Appendix B presents quotes from student presentations that highlight the lessons learned, and ordered by the 
frequency each graduate attribute was mentioned by a team.

Analysis shows that students realized that teamwork is essential to the success in engineering design projects. Students noted that they understood the importance of communication among team members, team meetings and the effective distribution of work among team members. Students also highlighted the criticality of project management. They reported that timelines were tight and planning milestones and sticking to their projects' timeline was critical to their success. Students reported on the importance of client feedback and indicated that they experienced the iterative nature of the engineering design process. In addition, students reflected that completing their projects required them to research topics and acquire knowledge from different engineering disciplines.

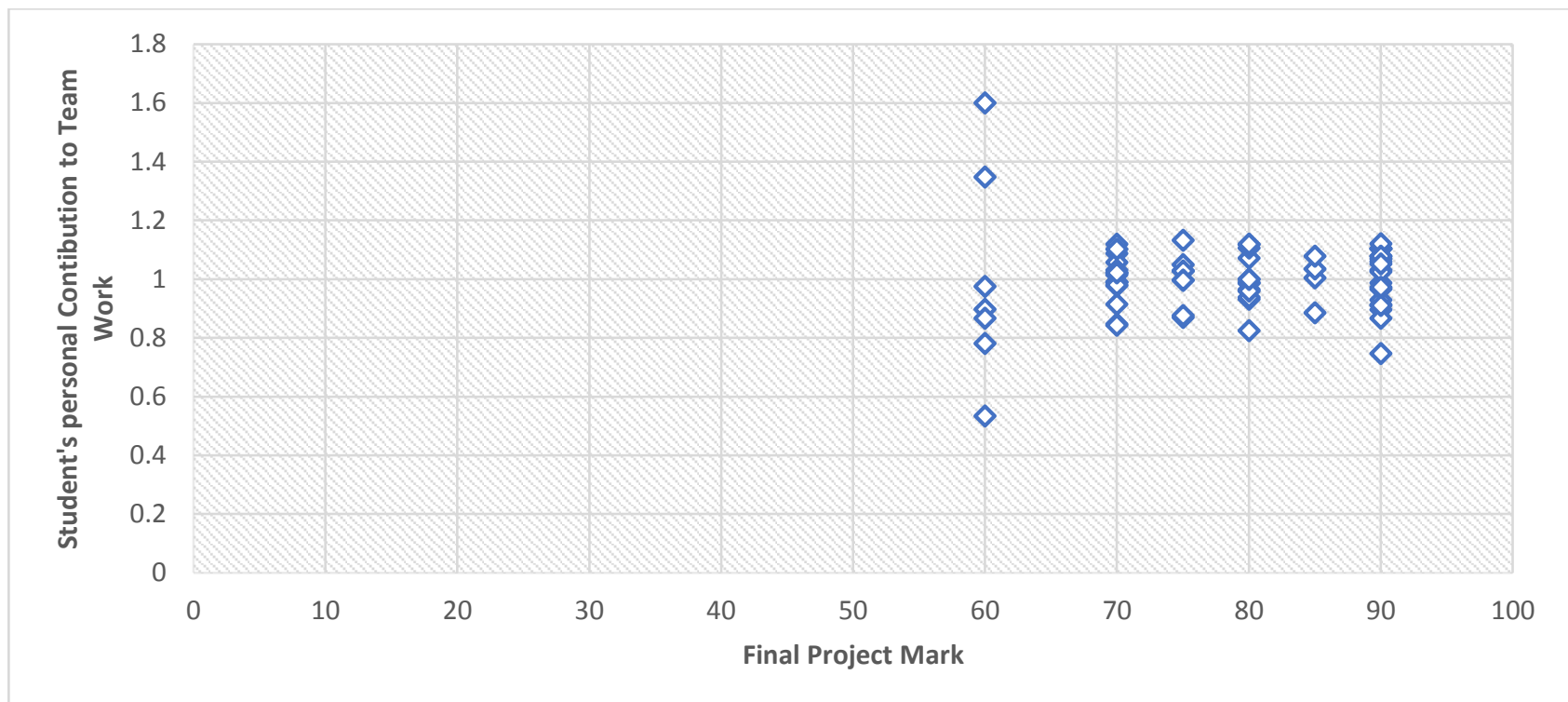

Fig. 2. The impact of team dynamics on final project marks.

\section{CONCLUSION}

This article describes the impact of an engineering design course on first-year engineering students. Results show that the use of a CPBL environment has allowed students to develop their design skills, as students showed substantial improvement in their design skills between the beginning and the end of the course.

Scaffolding strategies designed in the CPBL environment such as team dynamics, communication, use of engineering tools, and project management facilitated learning. All teams were successful in completing their projects by completing three cycles of iterations of their prototypes based on client feedback and only a few teams remained dysfunctional.

Furthermore, students were very engaged throughout the course and enjoyed working on a project that allowed them to interact with clients to gain feedback and solve their engineering problem. Many students articulated the need for better project management, which may indicate a need for more emphasis on project management during the course.

\section{References}

[1] V. Braun and V. Clarke, "Using thematic analysis in psychology," Qual. Res. Psychol., vol. 3, no. 2, pp. 77-101, Jan. 2006.

[2] M. Carroll, S. Goldman, L. Britos, J. Koh, A. Royalty, and M. Hornstein, "Destination, Imagination and the Fires Within: Design Thinking in a Middle School Classroom," Int. J. Art Des. Educ., vol. 29, no. 1, pp. 37-53, Feb. 2010.

[3] CEAB, "2016 Accreditation Criteria and Procedures," Engineers Canada, 2016.

[4] D. C. Davis, K. L. Gentili, M. S. Trevisan, and D. E. Calkins, "Engineering Design Assessment Processes and Scoring Scales for Program Improvement and Accountability," J. Eng. Educ., vol. 91, no. 2, pp. 211-221, Apr. 2002. 
[5] R. Donnelly and M. Fitzmaurice, "Collaborative Project-based Learning and Problem-based Learning in Higher Education: a Consideration of Tutor and Student Role in Learner-Focused Strategies," BooksBook Chapters, Jan. 2005.

[6] A. J. Dutson, R. H. Todd, S. P. Magleby, and C. D. Sorensen, "A Review of Literature on Teaching Engineering Design Through Project-Oriented Capstone Courses," J. Eng. Educ., vol. 86, no. 1, pp. 17-28, Jan. 1997.

[7] C. L. Dym, A. M. Agogino, O. Eris, D. D. Frey, and L. J. Leifer, "Engineering Design Thinking, Teaching, and Learning," J. Eng. Educ., vol. 94, no. 1, pp. 103-120, Jan. 2005.

[8] B. Frank and D. Strong, "Development of a Design Skill Assessment Tool," Proc. Can. Eng. Educ. Assoc., Jul. 2010.

[9] M. Galaleldin, F. Bouchard, H. Anis, and C. Lague, "The Impact of Makerspaces on Engineering Education," Proc. Can. Eng. Educ. Assoc., 2016.
[10] H. Pournaghshband, "The Students' Problems in Courses with Team Projects," in Proceedings of the Twenty-first SIGCSE Technical Symposium on Computer Science Education, New York, NY, USA, 1990, pp. 44-47.

[11] D. Wood, J. S. Bruner, and G. Ross, "The Role of Tutoring in Problem Solving*," J. Child Psychol. Psychiatry, vol. 17, no. 2, pp. 89-100, Apr. 1976.

[12] W. H. Wood, "Decision-based design: a vehicle for curriculum integration," Int. J. Eng. Educ., vol. 20, no. 3, pp. 433-439, 2004.

[13] "About Waterloo Cases in Design Engineering," Engineering Cases, 26-Apr-2013. [Online]. Available: https://uwaterloo.ca/engineeringcases/about. [Accessed: 15-May-2017].

[14] “ITP Metrics." [Online]. Available: https://www.itpmetrics.com/. [Accessed: 14-May2017].

\section{APPENDIX A: NEED IDENTIFICATION STAGE ADDED TO DSA RUBRIC ${ }^{1}$}

\begin{tabular}{|l|l|l|l|}
\hline \multirow{2}{*}{$\begin{array}{l}\text { Major } \\
\text { Category }\end{array}$} & \multicolumn{2}{|c|}{ Phrases to for: } & Score \\
\cline { 2 - 5 } & $\begin{array}{l}\text { Novice (1,2) } \\
\text { 'List Categories' }\end{array}$ & $\begin{array}{l}\text { Emerging (3,4) } \\
\text { Describing 'steps' } \\
\text { Refers to tools }\end{array}$ & $\begin{array}{l}\text { Established (5,6) } \\
\text { Applies steps to specific problem, } \\
\text { explains how steps accomplished, } \\
\text { describes use of tool'; } \\
\text { referenced }\end{array}$ \\
\hline $\begin{array}{l}\text { Need } \\
\text { Identification }\end{array}$ & $\begin{array}{l}\text { Identifies a } \\
\text { need/problem for } \\
\text { an engineering } \\
\text { design project }\end{array}$ & $\begin{array}{l}\text { Successfully } \\
\text { identifies a need, } \\
\text { empathizes with the } \\
\text { end user and } \\
\text { recognizes end } \\
\text { users existing } \\
\text { solutions to the } \\
\text { problem }\end{array}$ & $\begin{array}{l}\text { Interviews end users/stakeholders, } \\
\text { successfully defines the need, and the } \\
\text { end-user patterns of dealing with the } \\
\text { need. }\end{array}$ \\
\hline
\end{tabular}

\footnotetext{
${ }^{1}$ Refer to reference [8] for the original rubric.
} 


\section{APPENDIX B: THEMATIC ANALYSIS OF LESSONS LEARNED}

\begin{tabular}{|c|c|c|}
\hline $\begin{array}{l}\text { Code - Graduate } \\
\text { Attribute - }\end{array}$ & Quotes from Student Presentations & Frequency $^{2}$ \\
\hline $\begin{array}{l}\text { Project } \\
\text { Management }\end{array}$ & $\begin{array}{l}\text { - Making a detailed budget before buying everything we need } \\
\text { - } \text { Distribute work more effectively } \\
\text { - } \text { Have group meetings } \\
\text { - Start early } \\
\text { - } \text { Don't procrastinate! } \\
\text { - We bought too many materials, we should have better } \\
\text { - } \quad \text { Follow the construction aspect of our project } \\
\text { - } \quad \text { Buying materials beforehand } \\
\text { - Starting work earlier } \\
\text { - Assigning a leader to the team } \\
\text { - } \text { Creating a detailed plan and keeping track of progress } \\
\text { - Time management } \\
\text { - } \text { Documentation is time-consuming }\end{array}$ & 8 \\
\hline Design & $\begin{array}{l}\text { - Prototyping takes an obscene amount of time } \\
\text { - } \quad \text { Interpretation of Feedback } \\
\text { - Work on only one accessory to improve quality and lower } \\
\text { - } \text { costs } \\
\text { - Technical improvements to the project } \\
\text { - Examer More Client Feedback } \\
\text { time intervals }\end{array}$ & 6 \\
\hline $\begin{array}{l}\text { Individual and } \\
\text { Team work }\end{array}$ & $\begin{array}{l}\text { - } \text { Be Flexible } \\
\text { - } \text { Emphasize Communication between Team members } \\
\text { - } \text { Always stay connected and use a dedicated team chat } \\
\text { program } \\
\text { - Teamwork and group dynamics }\end{array}$ & 6 \\
\hline $\begin{array}{l}\text { Engineering } \\
\text { Knowledge }\end{array}$ & $\begin{array}{l}\text { - Supports vs Silicon Mummification } \\
\text { - } \quad \text { A sturdier container (different materials such as copper) } \\
\text { - } \quad \text { Better hook ups to the power source } \\
\text { - Better user experience (pump) }\end{array}$ & 3 \\
\hline Investigation & $\begin{array}{l}\text { - Invest more time in research of components } \\
\text { - } \quad \text { Research everything carefully }\end{array}$ & 2 \\
\hline Communication & $\begin{array}{ll}\text { - } & \text { Communication is key } \\
\text { - } & \text { Communication can be difficult }\end{array}$ & 1 \\
\hline
\end{tabular}

${ }^{2}$ Frequency refers to the number of student teams who mentioned this code. 